\title{
Valsartan attenuates pulmonary hypertension via suppression of mitogen activated protein kinase signaling and matrix metalloproteinase expression in rodents
}

\author{
YUYAN LU ${ }^{1 *}$, HAIPENG GUO ${ }^{2 *}$, YUXI SUN $^{1}$, XIN PAN $^{1}$, JIA DONG $^{1}$, \\ DI GAO ${ }^{1}$, WEI CHEN ${ }^{1}$, YAWEI XU ${ }^{1}$ and DACHUN XU ${ }^{1}$ \\ ${ }^{1}$ Department of Cardiology, Shanghai Tenth People's Hospital, Tongji University School of Medicine, \\ Shanghai 200072; ${ }^{2}$ Key Laboratory of Cardiovascular Remodeling and Function Research, Chinese Ministry of Education \\ and Chinese Ministry of Health, Qilu Hospital of Shandong University, Jinan, Shandong 250000, P.R. China
}

Received March 30, 2016; Accepted March 1, 2017

DOI: $10.3892 / \mathrm{mmr} .2017 .6706$

\begin{abstract}
It has previously been demonstrated that the renin-angiotensin system is involved in the pathogenesis and development of pulmonary hypertension ( $\mathrm{PH})$. However, the efficacy of angiotensin II type I (AT1) receptor blockers in the treatment of PH is variable. The present study examined the effects of the AT1 receptor blocker valsartan on monocrotaline (MCT)-induced $\mathrm{PH}$ in rats and chronic hypoxia-induced $\mathrm{PH}$ in mice. The results demonstrated that valsartan markedly attenuated development of $\mathrm{PH}$ in rats and mice, as indicated by reduced right ventricular systolic pressure, diminished lung vascular remodeling and decreased right ventricular hypertrophy, compared with vehicle treated animals. Immunohistochemical analyses of proliferating cell nuclear antigen expression revealed that valsartan suppressed smooth muscle cell proliferation. Western blot analysis demonstrated that valsartan limited activation of p38, c-Jun N-terminal kinase $1 / 2$ and extracellular signal-regulated kinase 1/2 signaling pathways and significantly reduced MCT-induced upregulation of pulmonary matrix metalloproteinases- 2 and -9 , and transforming growth factor- $\beta 1$ expression. The results suggested that valsartan attenuates development of $\mathrm{PH}$ in rodents by reducing expression of extracellular matrix remodeling factors and limiting smooth muscle cell proliferation to decrease pathological vascular remodeling. Therefore, valsartan may be a valuable future therapeutic approach for the treatment of $\mathrm{PH}$.
\end{abstract}

Correspondence to: Dr Dachun Xu, Department of Cardiology, Shanghai Tenth People's Hospital, Tongji University School of Medicine, 301 Middle Yanchang Road, Shanghai 200072, P.R. China E-mail: xdc77@aliyun.com

${ }^{*}$ Contributed equally

Key words: valsartan, pulmonary hypertension, mitogen-activated protein kinase, matrix metalloproteinases

\section{Introduction}

Patients with pulmonary hypertension (PH) have a 5-year survival $\sim 65 \%$ (1) and is defined by an increase in the mean pulmonary artery pressure $>25 \mathrm{mmHg}$ at rest (1-4). Based on various clinical and hemodynamic features, $\mathrm{PH}$ is classified into several subgroups, which share similar symptom, such as increased breathlessness, worsening right heart failure and eventually death $(1,4)$ and similar pathological characteristics, including sustained vasoconstriction and progressive pulmonary vascular remodeling (5). Previous studies demonstrated that vascular cells, such as endothelial, smooth muscle and adventitial fibroblast cells and the extracellular matrix (ECM) had an important role in vasculopathy, including intimal and medial thickening, plexiform lesions, fibrosis and ECM deposition $(5,6)$. Therefore, strategies that target vasoconstriction and vascular remodeling and preserve the structure and function of the pulmonary vasculature may potentially be used to attenuate the pathological progression of $\mathrm{PH}$.

Angiotensin II (AngII) is considered to contribute to pathological vascular remodeling. Notably, expression of angiotensin converting enzyme and AngII type 1 (AT1) receptor are increased in pulmonary vasculature of $\mathrm{PH}$ models (7-9). Previous studies have demonstrated that losartan (10-12) and telmisartan (13) attenuate pulmonary hypertension in humans and animal models, however other studies failed to demonstrate beneficial effects of angiotensin receptor blockers (ARBs) on $\mathrm{PH}$ (14). These contradictory results caused by various factors, including differing drug performances and dosages of the ARBs. The majority available data regarding valsartan is predominantly derived from hypertensive studies, however, there is evidence that valsartan has other beneficial effects on heart failure, including regression in ventricular remodeling and improvement of systemic vascular resistance (15-17). Therefore, based on the observed protective effects of valsartan against inflammation, reactive oxygen species (ROS) production and tissue remodeling, the present study hypothesized that valsartan may be effective in attenuating $\mathrm{PH}$ development. Two animal models were used to evaluate the efficacy of valsartan on $\mathrm{PH}$. 


\section{Materials and methods}

Ethics. The present study was approved by the Animal Care and Use Committee of Tongji University (Shanghai, China) and conducted in accordance with the National Institutes of Health Guide for the Care and Use of Laboratory Animals (18). Measurements of hemodynamics were performed under anesthesia and all efforts were made to minimize the animal suffering and distress.

Animal models and experimental design. To examine the effects of valsartan on $\mathrm{PH}$, the present study used two animal models: Monocrotaline (MCT)-induced PH model (drug and toxin induced pulmonary arterial hypertension) and a hypoxia-induced PH model (pulmonary hypertension due to lung diseases and/or hypoxia) (2). Male Sprague-Dawley rats (110-130 g) and male C57BL/6 mice (22-26 g) were purchased from Shanghai Slac Laboratory Animal Co., Ltd (Shanghai, Chain) and housed in standard cages given water and normal diet under room temperature in controlled light conditions (a $12 \mathrm{~h}$ light/dark cycle).

As previously described, MCT (Oakwood Products Inc., SC, USA) was dissolved in $0.5 \mathrm{~N} \mathrm{HCl}$ and was adjusted to $\mathrm{pH} 7.4$ with $0.5 \mathrm{~N} \mathrm{NaOH}$ (19). The solution was administered as a single subcutaneous injection ( $40 \mathrm{mg} / \mathrm{kg}$ ) to male rats to induce PH (19). Rats received a single injection of MCT or saline (control group, $n=6$ ). Following MCT injection, animals were treated with valsartan (MCT + valsartan $20 \mathrm{mg} / \mathrm{kg}$ group, $\mathrm{n}=7$; MCT + valsartan $40 \mathrm{mg} / \mathrm{kg}$ group, $\mathrm{n}=6$ ) or vehicle (an equal volume of saline, MCT group, $n=8$ ) once daily by gavage for 3 weeks. Valsartan was purchased from Novartis China (Beijing, China).

Male mice were exposed to hypobaric hypoxia as described previously (20). Briefly, the pressure chamber was decreased progressively from $0.8 \mathrm{~atm}\left(16.9 \% \mathrm{O}_{2}\right)$ on day 1 to $0.5 \mathrm{~atm}$ $\left(10.5 \% \mathrm{O}_{2}\right)$ following day 7 and was maintained at $10.5 \% \mathrm{O}_{2}$ for a further 3 weeks. The chamber was opened once every week for cleaning and feeding. Mice exposed to hypobaric hypoxia were randomly divided into 2 groups for oral administration of valsartan (hypoxia $+20 \mathrm{mg} / \mathrm{kg}$ valsartan group, $\mathrm{n}=10$; hypoxia $+40 \mathrm{mg} / \mathrm{kg}$ valsartan group, $\mathrm{n}=10$ ) or vehicle (an equal volume of saline, hypoxia group, $n=19$ ). Control mice were maintained in normobaric conditions $(n=8)(20)$.

Measurements of aortic pressure and right ventricular $(R V)$ hemodynamics. Following anaesthetization and tracheotomy of rats, a polyethylene catheter was introduced via the right common carotid artery for measurement of systemic arterial pressure 3 weeks after MCT injection. A right heart catheter was then introduced into the right external jugular vein and the tip advanced into the right ventricle until a typical right ventricular pressure wave pattern appeared, as described previously $(19,20)$. Hemodynamic parameters were assessed by a polygraph system (PowerLab 8/30; ADInstruments, Bella Vista, NSW, Australia).

After 4 weeks of hypobaric hypoxia treatment, mice were anesthetized and intubated with a 20-gauge Teflon tube attached to a MiniVent type 845 mouse ventilator (Hugo Sachs Elektronik GmbH, Germany). A pressure catheter was introduced via the right common carotid artery into the ascending aorta for measurement of systolic and diastolic blood pressures and left ventricular (LV) hemodynamics were measured as previously described (21). For RV hemodynamics, open-chest RV catheterization was performed during anesthesia with $1.5 \%$ isoflurane. Data were collected when a steady state was reached $(19,20)$.

Sample preparation. Following hemodynamic assessment at the aforementioned indicated time point, all rats and mice were euthanized by exsanguination and the heart, lung and other major organs were harvested. Lung weight was measured and the left lung was frozen in liquid nitrogen until biochemical analysis. The airways of the top right lobe were perfused with and fixed in $10 \%$ buffered formalin for histological analysis. The RV free wall was dissected from the left ventricular septum $(\mathrm{LV}+\mathrm{S})$ and weighed separately. The ratio of $\mathrm{RV} /(\mathrm{LV}+\mathrm{S} ; \mathrm{g} / \mathrm{g}$ ) and $\mathrm{RV} /$ body weight $(\mathrm{BW} ; \mathrm{mg} / \mathrm{g})$ were calculated as an index of RV hypertrophy $(19,20)$.

Histological analysis. Following hemodynamic measurements, rat lung tissue was fixed in $10 \%$ formalin for $>24 \mathrm{~h}$, dehydrated, embedded in paraffin and subsequently sectioned at $5 \mu \mathrm{m}$ for morphometric analyses. Pulmonary vascular muscularization was determined by hematoxylin and eosin staining, using Olympus Inverted Microscope IX83 (Olympus Corporation, Tokyo, Japan). Briefly, the medial wall thickness of the arteries with a diameter of 50-100 $\mu \mathrm{m}$ was calculated, according to the following formula: Medial thickness $(\%)=2 \times$ medial wall thickness/arterial external diameter x 100. Additionally, a total of 60 intra-acinar arteries were examined in each rat and categorized as non-muscular, partially muscular or fully muscular arteries (19) and the relative percentage were calculated. Lung fibrosis was detected using Masson's Trichrome Stain kit (cat. no. BB-44222-1; Bestbio, Shanghai, China, http://www.bestbio.com.cn/).

Immunohistochemical analysis. In order to evaluate proliferating cells, proliferating cell nuclear antigen (PCNA, cat. no. sc-25280; Santa Cruz Biotechnology, Inc., Dallas, TX, USA) staining was performed in rat lung tissue sections. Slides $(5 \mu \mathrm{m})$ were dry-heated at $65^{\circ} \mathrm{C}$ for $1 \mathrm{~h}$, deparaffinized with xylene, and rehydrated in serial dilutions of ethanol. Antigen retrieval was performed by incubation in citrate buffer for $20 \mathrm{~min}$ at $95-100^{\circ} \mathrm{C}$, followed by washing in PBS. The sections were incubated with $3 \% \mathrm{H}_{2} \mathrm{O}_{2}$ in PBS for $20 \mathrm{~min}$ followed by $10 \%$ normal goat serum blocking solution (cat. no. 50062Z; Thermo Fisher Scientific, Inc., Waltham, MA, USA) for $30 \mathrm{~min}$ at room temperature. Sections were then incubated with a mouse monoclonal primary antibody against PCNA (1:200) overnight at $4^{\circ} \mathrm{C}$, followed by incubation with rabbit anti-mouse biotinylated horseradish peroxidase-conjugated secondary antibody (cat. no. GP016129; Gene Tech Biotechnology, Shanghai, China) at the dilution of 1:200 for $1 \mathrm{~h}$ at room temperature. The percentage of PCNA-positive cells were calculated in 10 randomly chosen fields of each section using an inverted microscope IX83 at x400 magnification $(22,23)$.

Western blot analysis. Rat lung tissues were homogenized using a cell lysis buffer supplemented with protease inhibitor 
Table I. Morphometric parameters of rats at sacrifice.

\begin{tabular}{lcccc}
\hline & \multicolumn{3}{c}{ Group } \\
\cline { 2 - 5 } Feature & \multicolumn{3}{c}{$\begin{array}{c}\text { MCT + valsartan } \\
(20 \mathrm{mg} / \mathrm{kg})\end{array}$} & $\begin{array}{c}\text { MCT + valsartan } \\
(40 \mathrm{mg} / \mathrm{kg})\end{array}$ \\
\hline No. of rats & Control & 8 & 7 & 6 \\
BW $(\mathrm{g})$ & 6 & $213.75 \pm 5.46^{\mathrm{b}}$ & $208.43 \pm 3.57$ & $0.14 \pm 0.01$ \\
RV $(\mathrm{g})$ & $251.86 \pm 4.13$ & $0.18 \pm 0.01^{\mathrm{b}}$ & $0.49 \pm 0.03$ & $0.14 \pm 0.01^{\mathrm{c}}$ \\
$\mathrm{LV}+\mathrm{S}(\mathrm{g})$ & $0.11 \pm 0.01$ & $0.54 \pm 0.01$ & $0.63 \pm 0.03$ & $0.49 \pm 0.03$ \\
Ventricle $(\mathrm{g})$ & $0.56 \pm 0.02$ & $0.71 \pm 0.02$ & $0.30 \pm 0.03$ & $0.63 \pm 0.03$ \\
RV/(LV+S) $(\mathrm{g} / \mathrm{g})$ & $0.67 \pm 0.03$ & $0.33 \pm 0.02^{\mathrm{b}}$ & $0.69 \pm 0.07$ & $0.27 \pm 0.01^{\mathrm{c}}$ \\
RV/BW $(\mathrm{mg} / \mathrm{g})$ & $0.19 \pm 0.01$ & $0.84 \pm 0.06^{\mathrm{b}}$ & $0.13 \pm 0.02$ & $0.65 \pm 0.04^{\mathrm{c}}$ \\
RA $(\mathrm{g})^{\mathrm{a}}$ & $0.42 \pm 0.03$ & $0.13 \pm 0.02$ & $0.16 \pm 0.02$ & $0.12 \pm 0.01$ \\
$\mathrm{LA}(\mathrm{g})^{\mathrm{a}}$ & $0.10 \pm 0.01$ & $0.15 \pm 0.02$ & $0.88 \pm 0.17$ & $0.13 \pm 0.02$ \\
RA/LA $(\mathrm{g} / \mathrm{g})^{\mathrm{a}}$ & $0.14 \pm 0.01$ & $0.87 \pm 0.04$ & $0.96 \pm 0.12$ \\
\hline
\end{tabular}

${ }^{\mathrm{a}} \mathrm{n}=5$ in MCT group. ${ }^{\mathrm{b}} \mathrm{P}<0.01$ vs. control. ${ }^{\mathrm{c}} \mathrm{P}<0.05$ vs. MCT group. Data are presented as the mean \pm standard error. BW, body weight; LA, left atria; $\mathrm{LV}+\mathrm{S}$, left ventricular septum; $\mathrm{MCT}$, monocrotaline; $\mathrm{RA}$, right atria; $\mathrm{RV}$, right ventricle.
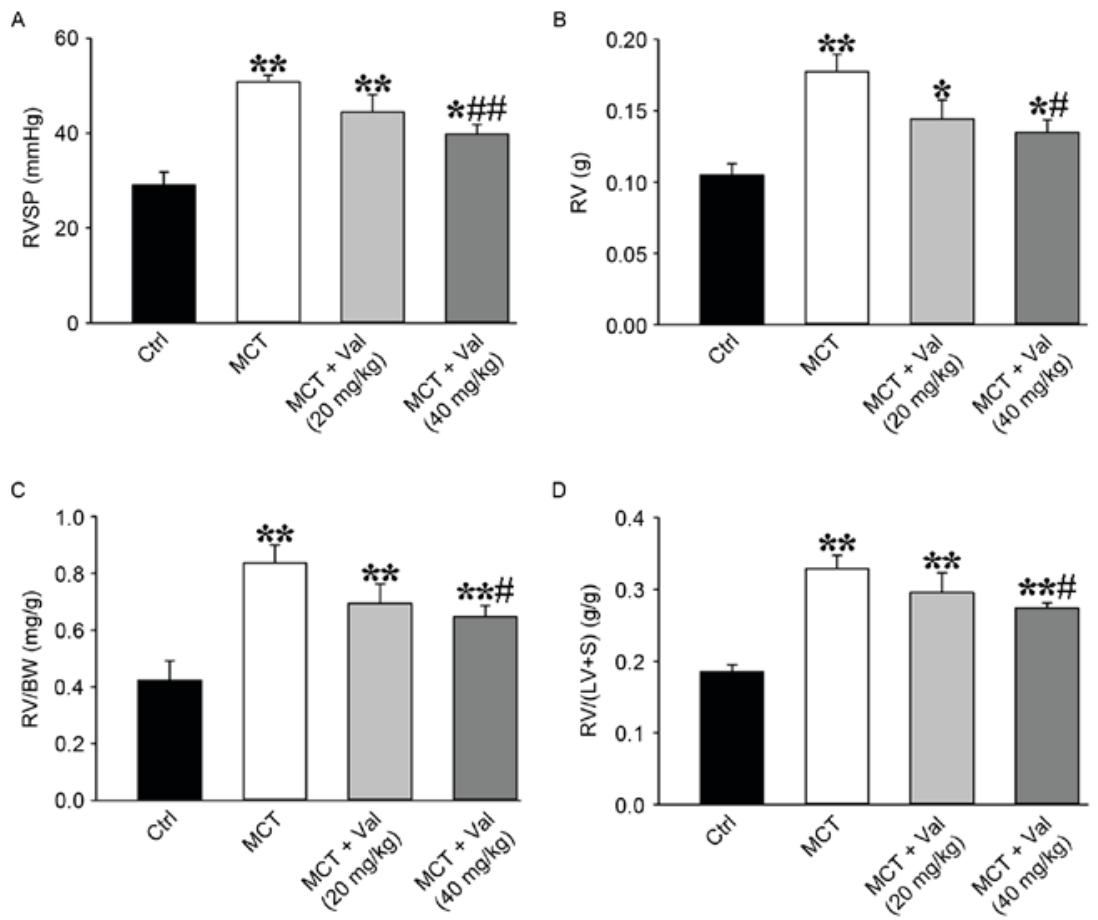

Figure 1. Valsartan reduces MCT-induced increased RVSP and RV hypertrophy index. Valsartan treatment significantly attenuated MCT-induced increases of (A) RVSP, RV hypertrophy as indicated by (B) RV weight, (C) the ratio of RV weight to BW and (D) the ratio of RV weight to (LV+S) weight (Ctrl group, n=6; MCT group, $\mathrm{n}=8 ; \mathrm{MCT}+\mathrm{Val}(20 \mathrm{mg} / \mathrm{kg})$ group $\mathrm{n}=7 ; \mathrm{MCT}+\mathrm{Val}(40 \mathrm{mg} / \mathrm{kg})$ group, $\mathrm{n}=6)$. Results are expressed as the mean \pm standard error. "P<0.05, ${ }^{* *} \mathrm{P}<0.01$ vs. Ctrl; ${ }^{~} \mathrm{P}<0.05,{ }^{\# \#} \mathrm{P}<0.01$ vs. MCT group. BW, body weight; Ctrl, control; LV, left ventricle; $\mathrm{MCT}$, monocrotaline; RV, right ventricle; RVSP, right ventricular systolic pressure; S, septum; Val, valsartan.

(cat nos. 9803 and 5871; Cell Signaling Technology, Billerica, MA, USA) using a tissue homogenizer and the protein concentrations were assessed using a BCA Protein Assay kit (cat. no. 23225; Thermo Fisher Scientific, Inc.). Protein samples (40 $\mu \mathrm{g}$ total protein/well) were separated with $10 \%$ SDS-polyacrylamide gel electrophoresis and transferred to a nitrocellulose membrane. Membranes were blocked with 5\% BSA (cat. no. 97061-416; VWR International, Radnor, PA,
USA) in $0.1 \%$ TBS Tween-20 for $1 \mathrm{~h}$ at room temperature prior to $4^{\circ} \mathrm{C}$ overnight incubation with the indicated primary antibodies, followed by incubation with goat anti-mouse and donkey anti-rabbit fluorescent secondary antibodies (cat. nos. 926-32220 and 926-32213; LiCor Biosciences, Lincoln, TN, USA) at the dilution of $1: 10,000$ for $1 \mathrm{~h}$ in the dark at room temperature. The membranes were visualized using the Odyssey system (LiCor Biosciences) and the relative protein 
Table II. Anatomic data of control, hypoxia and hypoxia + valsartan groups.

\begin{tabular}{lcccc}
\hline & \multicolumn{3}{c}{ Experimental group } \\
\cline { 2 - 5 } Feature & Control & Hypoxia & $\begin{array}{c}\text { Hypoxia + valsartan } \\
(20 \mathrm{mg} / \mathrm{kg})\end{array}$ & $\begin{array}{c}\text { Hypoxia + valsartan } \\
(40 \mathrm{mg} / \mathrm{kg})\end{array}$ \\
\hline No. of mice & 8 & 19 & 10 & 10 \\
BW $(\mathrm{g})$ & $25.08 \pm 0.63$ & $24.50 \pm 0.32$ & $24.99 \pm 0.36$ & $24.38 \pm 0.55$ \\
Heart $(\mathrm{g})$ & $0.1085 \pm 0.0042$ & $0.1160 \pm 0.0025$ & $0.1132 \pm 0.0017$ & $0.1107 \pm 0.0017$ \\
Lung $(\mathrm{g})$ & $0.1322 \pm 0.0056$ & $0.1874 \pm 0.0024^{\mathrm{a}}$ & $0.1852 \pm 0.0031$ & $0.1741 \pm 0.0040^{\mathrm{b}}$ \\
Liver $(\mathrm{g})$ & $0.8833 \pm 0.0412$ & $0.8829 \pm 0.0114$ & $0.8939 \pm 0.0277$ & $0.8787 \pm 0.0218$ \\
Kidney $(\mathrm{g})$ & $0.2668 \pm 0.0050$ & $0.2724 \pm 0.0051$ & $0.2669 \pm 0.0064$ & $0.2596 \pm 0.0069$ \\
Spleen $(\mathrm{g})$ & $0.0679 \pm 0.0023$ & $0.0676 \pm 0.0016$ & $0.0670 \pm 0.0013$ & $0.0651 \pm 0.0013$ \\
RA $(\mathrm{g})$ & $0.0028 \pm 0.0001$ & $0.0044 \pm 0.0001^{\mathrm{a}}$ & $0.0042 \pm 0.0002$ & $0.0039 \pm 0.0003$ \\
LA $(\mathrm{g})$ & $0.0028 \pm 0.0003$ & $0.0027 \pm 0.0001$ & $0.0028 \pm 0.0001$ & $0.0027 \pm 0.0001$ \\
RV $(\mathrm{g})$ & $0.0197 \pm 0.0006$ & $0.0318 \pm 0.0011^{\mathrm{a}}$ & $0.0299 \pm 0.0008$ & $0.0279 \pm 0.0009^{\mathrm{c}}$ \\
LV+S $(\mathrm{g})$ & $0.0832 \pm 0.0035$ & $0.0770 \pm 0.0016$ & $0.0763 \pm 0.0010$ & $0.0762 \pm 0.0011$ \\
RV/(LV+S) $(\mathrm{g} / \mathrm{g})$ & $0.2381 \pm 0.0067$ & $0.4115 \pm 0.0084^{\mathrm{a}}$ & $0.3925 \pm 0.0101$ & $0.3662 \pm 0.0115^{\mathrm{c}}$ \\
RV/BW $(\mathrm{mg} / \mathrm{g})$ & $0.7858 \pm 0.0189$ & $1.2962 \pm 0.0378^{\mathrm{a}}$ & $1.2006 \pm 0.0418$ & $1.1490 \pm 0.0449^{\mathrm{b}}$ \\
\hline
\end{tabular}

Data are presented as the mean \pm standard error. ${ }^{\mathrm{P}} \mathrm{P}<0.01$ vs. control; ${ }^{\mathrm{b}} \mathrm{P}<0.05,{ }^{\mathrm{c}} \mathrm{P}<0.01$ vs. hypoxia group. BW, body weight; LA, left atria; $\mathrm{LV}+\mathrm{S}$, left ventricular septum; RA, right atria; $\mathrm{RV}$, right ventricle.

levels were quantified using Image J version 1.4.3.67 (imagej. nih.gov/ij/). Antibodies for total and phosphorylated extracellular regulated kinase (ERK) 1/2 (cat. nos. 9102 and 4370), c-Jun N-terminal kinase (JNK) 1/2 (cat. nos. 9252 and 9255), p38 (cat. nos. 9212 and 4511), cyclin D1 (cat. no. 2978), histone H3 (cat. no. 4499) and $\beta$-actin (cat. no. 3700), where total and phosphorylated ERK1/2, JNK1/2, p38, cyclin D1 and histone $\mathrm{H} 3$ were diluted at 1:1,000 and $\beta$-actin was diluted at 1:2,000 and purchased from Cell Signaling Technology, Inc. The antibodies for PCNA (cat. no. sc-25280; 1:300) and transforming growth factor $\beta 1$ (TGF- $\beta 1$, cat. no. sc-146; 1:1,000) were purchased from Santa Cruz Biotechnology, Inc. Antibodies for matrix metalloproteinases (MMP)-2 (cat. no. ab37150; 1:500) and MMP-9 (cat. no. ab38898; 1:800) were purchased from Abcam (MA, USA).

Statistical analysis. All values are expressed as the mean \pm standard error. Differences among multiple groups were analyzed by one-way analysis of variance, followed Bonferroni's correction as a post-hoc analysis. Statistical analysis was performed using SPSS version 13.0 (SPSS Inc., Chicago, IL, USA). $\mathrm{P}<0.05$ was considered to indicate a statistically significant difference.

\section{Results}

Valsartan significantly attenuates MCT-induced increase of $R V$ pressure and $R V$ hypertrophy in rats. The MCT group developed severe $\mathrm{PH}$ at day 21 with increased RV systolic pressure (RVSP; a marker of systolic pulmonary pressure) compared with control group (Fig. 1A and Table I). Valsartan treatment dose-dependently suppressed development of PH in the low and high-dose valsartan groups (a marked reduction in RVSP by 13 and $21 \%$, respectively, compared with the MCT group; $\mathrm{P}=0.15$ and $\mathrm{P}=0.01$ ). In addition, valsartan at the concentration of $40 \mathrm{mg} / \mathrm{kg}$ reversed MCT-induced increase of RV hypertrophy, as indicated by increased $\mathrm{RV}, \mathrm{RV} / \mathrm{BW}$, and $\mathrm{RV} /(\mathrm{LV}+\mathrm{S})$ (Fig. 1B-D and Table I). These findings demonstrated that $40 \mathrm{mg} / \mathrm{kg}$ valsartan treatment significantly suppressed MCT-induced increase of RVSP and RV hypertrophy. It is of note that the mean systemic arterial pressure was significantly decreased in the MCT group $(95 \pm 5 \mathrm{mmHg})$ compared with control group $(109 \pm 2$ $\mathrm{mmHg} ; \mathrm{P}<0.01)$. However, valsartan did not affect systemic arterial pressure in low and high-dose groups at day $21(92 \pm 8$ and $90 \pm 8 \mathrm{mmHg}$, respectively) compared with MCT group.

Valsartan ameliorated hypoxia-induced increase of $R V$ pressure and $R V$ hypertrophy in mice. To confirm the effects of valsartan on $\mathrm{PH}$, a hypoxia-induced $\mathrm{PH}$ mice model was used in the present study. Consistent with the results in MCT-induced PH rat model, mice treated with high-dose valsartan exhibited significant decreases in hypoxia-induced increase of RVSP (Fig. 2A). Additionally, high-dose valsartan significantly reduced RV hypertrophy, such as RV weight from $0.032 \pm 0.001 \mathrm{~g}$ in the hypoxia group to $0.028 \pm 0.001 \mathrm{~g}$ in hypoxia+valsartan $(40 \mathrm{mg} / \mathrm{kg})$ group $(\mathrm{P}<0.05$; Fig. $2 \mathrm{~B}$ and Table II), RV/BW from $1.30 \pm 0.04 \mathrm{mg} / \mathrm{g}$ in the hypoxia group decreasing to $1.15 \pm 0.04 \mathrm{mg} / \mathrm{g}$ in hypoxia+valsartan $(40 \mathrm{mg} / \mathrm{kg})$ group, $(\mathrm{P}<0.05$; Fig. $2 \mathrm{C}$ and Table II $)$, and $\mathrm{RV} /(\mathrm{LV}+\mathrm{S})$ from $0.41 \pm 0.01 \mathrm{~g} / \mathrm{g}$ in hypoxia group decreasing to $0.37 \pm 0.01 \mathrm{~g} / \mathrm{g}$ in hypoxia+valsartan $(40 \mathrm{mg} / \mathrm{kg})$ group $(\mathrm{P}<0.05$; Fig. $2 \mathrm{D}$ and Table II). The data therefore suggested that $40 \mathrm{mg} / \mathrm{kg}$ valsartan treatment effectively attenuated the development of $\mathrm{PH}$ in the mouse hypoxia and rat MCT models.

Valsartan attenuated MCT-induced pulmonary vascular remodeling and lung fibrosis in rats. Histological and 

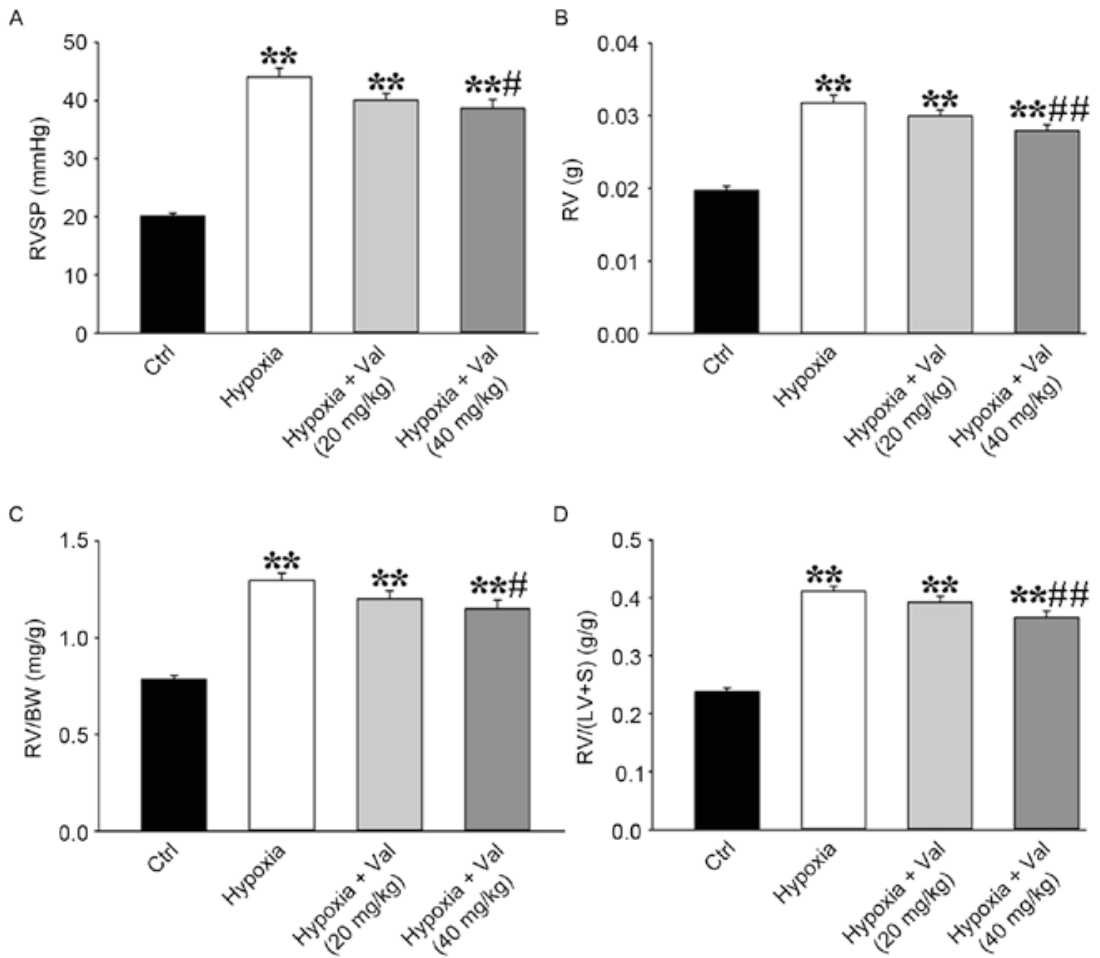

Figure 2. Valsartan inhibits increased RVSP and RV hypertrophy index induced by hypoxia. Valsartan treatment in mice attenuated hypoxia-induced increases of (A) RVSP, RV hypertrophy as indicated by (B) RV weight, (C) the ratio of RV weight to BW and (D) the ratio of RV weight to (LV + S) weight (Ctrl group, $\mathrm{n}=8$; hypoxia group, $\mathrm{n}=19$; hypoxia+Val $(20 \mathrm{mg} / \mathrm{kg})$ group, $\mathrm{n}=10$; hypoxia+Val $(40 \mathrm{mg} / \mathrm{kg})$ group, $\mathrm{n}=10)$. Results are expressed as the mean \pm standard error. ${ }^{* *} \mathrm{P}<0.01$ vs. Ctrl; ${ }^{\#} \mathrm{P}<0.05$, ${ }^{\# \#} \mathrm{P}<0.01$ vs. hypoxia group. BW, body weight; Ctrl, control; LV, left ventricular; RV, right ventricle; RVSP, right ventricular systolic pressure; S, septum; Val, valsartan.

biochemical analysis of lung tissues was performed to examine whether valsartan influences pulmonary vascular remodeling in the MCT-induced PH model. In comparison with vehicle treated MCT model rats, valsartan treatment significantly reduced lung vessel medial wall thickness of arteries with an external diameter of 50-100 $\mu \mathrm{m}(\mathrm{P}<0.05)$ and the ratio of fully muscularized distal pulmonary arteries to total number of arteries $(\mathrm{P}<0.01$; Fig. 3$)$.

PCNA expression is a marker for cell proliferation. Immunohistochemical analysis of lung tissue from control and valsartan treated animals revealed that valsartan treatment significantly reduced the percentage of PCNA-positive cells in the lung vessels compared with MCT group $(\mathrm{P}<0.01$; Fig. 4A and $\mathrm{B})$. Increased cell proliferation is indicative of increased progression through the cell cycle and western blot analysis indicated that valsartan significantly reduced cyclin D1 and PCNA protein expression (Fig. 4C-E).

Perivascular fibrosis is a common indicator of vascular inflammation and tissue remodeling that occurs in $\mathrm{PH}$. Masson's trichrome staining revealed that valsartan treatment reduced the number of dense focal collagen deposits induced by MCT treatment, compared with vehicle treated animals (Fig. 4A).

Valsartan attenuates MCT-induced increase of lung mitogen-activated protein kinase (MAPK) signaling pathways in rats. MAPK signaling is important in cell growth and proliferation. Therefore, the present study determined if valsartan influenced MAPK activation in the lung of MCT-treated rats. Among the four groups, differences in the total protein expression of p38, JNK1/2, ERK1/2 failed to reach statistical significance (Fig. 5). However, there was a significant increase in the phosphorylation of $\mathrm{p} 38, \mathrm{JNK} 1 / 2$ and ERK1/2 in the MCT group compared with control group $(\mathrm{P}<0.05)$. Valsartan treatment reduced the MCT-induced phosphorylation of $\mathrm{p} 38$, JNK1/2 and ERK1/2 $(\mathrm{P}<0.05)$.

Valsartan attenuated MCT-induced expression of lung MMPs and TGF- $\beta 1$ in rats. MMP-2 and -9 degrade ECM components and are important in smooth muscle cell migration, tissue remodeling and PH development (13). Consistent with increased tissue remodeling in the PH model, MCT resulted in a significant upregulation of lung MMP-2 and -9 expression. The increase in MMP-2 and -9 expression however, was significantly attenuated by valsartan treatment (Fig. 6). Valsartan significantly attenuated lung MMP-2 and -9 activity, as indicated by reduced cleavage to the lower molecular weight active form (Fig. 6A-C). TGF- $\beta 1$ is an established tissue remodeling factor that promotes fibrosis and smooth muscle cell proliferation in PH (20). MCT resulted in a significant increase of lung TGF- $\beta 1$ protein content, which was significantly diminished by valsartan treatment (Fig. 6A and D). These data indicated that valsartan reduced expression of tissue remodeling factors in $\mathrm{PH}$.

\section{Discussion}

The present study demonstrated that valsartan significantly attenuated the development of PH and right ventricular hypertrophy in two $\mathrm{PH}$ animal models. The protective effects were 


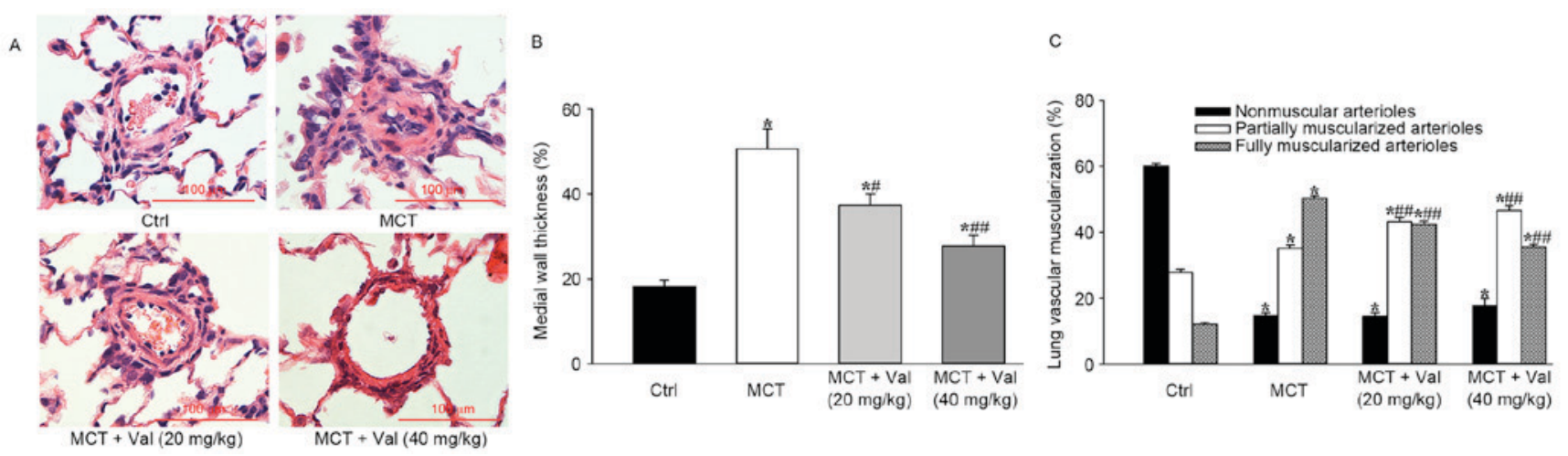

Figure 3. Effects of valsartan on MCT-induced pulmonary vascular remodeling. (A) Hematoxylin and eosin stained lung sections demonstrate that valsartan ameliorated MCT-induced pulmonary vascular remodeling in rats ( $\mathrm{n}=5$ rats per group). (B) The medial wall thickness of arteries with an external diameter of 50-100 $\mu \mathrm{m}$ ( $\mathrm{n}=5$ rats per group). (C) Distribution of nonmuscular, partially and fully muscularized small arteries in rats ( $\mathrm{n}=5$ rats per group). Results are expressed as the mean \pm standard error. ${ }^{*} \mathrm{P}<0.01$ vs. Ctrl; ${ }^{\#} \mathrm{P}<0.05,{ }^{\# \#} \mathrm{P}<0.01$ vs. MCT group. Ctrl, control; MCT, monocrotaline; Val, valsartan.
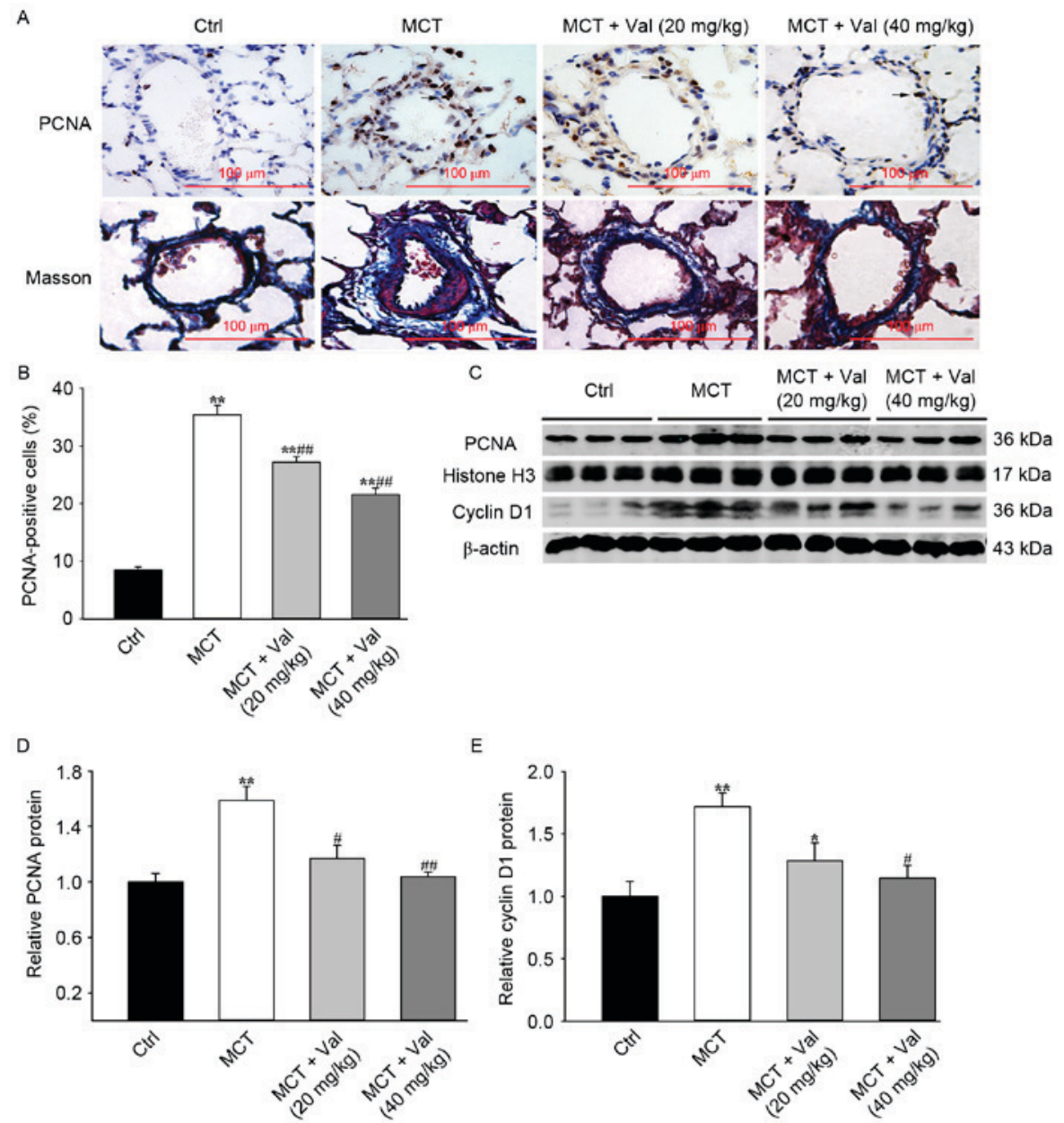

Figure 4. Inhibitory effects of valsartan on cell proliferation and fibrosis in rat lung tissue. MCT-induced increase in (A) lung fibrosis and (B) PCNA-positive cells was reduced by treatment with valsartan ( $\mathrm{n}=5$ rats per group). (C) Representative western blot of protein expression levels of PCNA, cyclin D1, histone $\mathrm{H} 3$ and $\beta$-actin. Quantification of (D) PCNA/histone H3 and (E) cyclin D1/ $\beta$-actin protein expression levels (n=5 rats per group). Results are expressed as the mean \pm standard error. ${ }^{*} \mathrm{P}<0.05,{ }^{* *} \mathrm{P}<0.01$ vs. Ctrl; ${ }^{*} \mathrm{P}<0.05,{ }^{\# \#} \mathrm{P}<0.01$ vs. MCT group. Ctrl, control; MCT, monocrotaline; PCNA, proliferating cell nuclear antigen; Val, valsartan.

modulated, in part, by the inhibition of MAPK signaling. Furthermore, valsartan reduced expression of lung MMP-2, -9 and TGF- $\beta 1$ in rats. These findings suggested that valsartan suppressed pulmonary vascular remodeling and attenuated development of PH in the rodents.
Previous studies have indicated that the renin-angiotensin system is involved in development of PH (7-9). Angiotensin and the AT1 receptor have been demonstrated to exhibit an increase in PH patients (9), and beneficial effects of ARBs, including losartan and telmisartan, have been confirmed in 


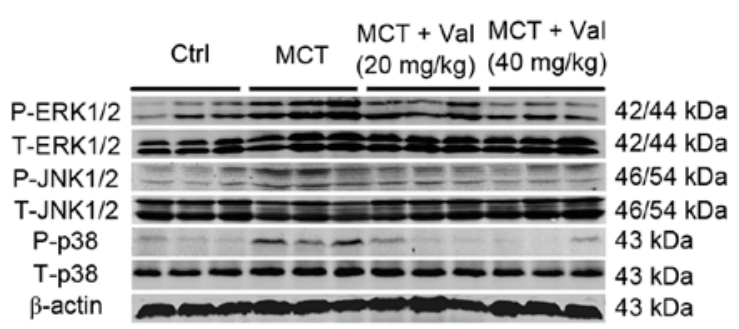

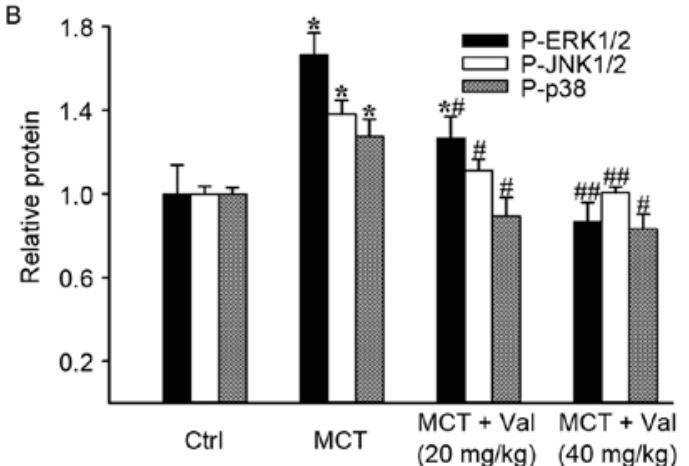

Figure 5. Effects of valsartan on MCT-induced phosphorylation of p38, JNK and ERK in lung tissue. (A) Representative blot of total and phosphorylated protein expression levels of $\mathrm{p} 38$, JNK and ERK detected by western blot analysis ( $\mathrm{n}=5$ rats per group). (B) Quantification of phosphorylated protein expression levels of $\mathrm{p} 38$, JNK and ERK relative to total p38, JNK and ERK. Results are expressed as the mean \pm standard error. ${ }^{*} \mathrm{P}<0.05$ vs. Ctrl; ${ }^{~} \mathrm{P}<0.05$,

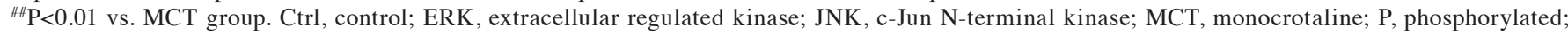
T, total; Val, valsartan

A

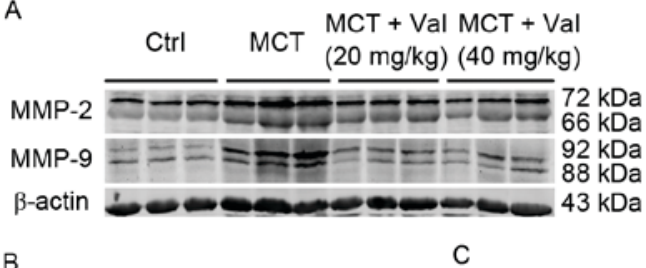

B

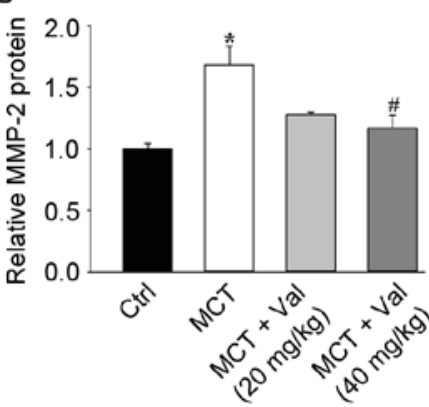

C

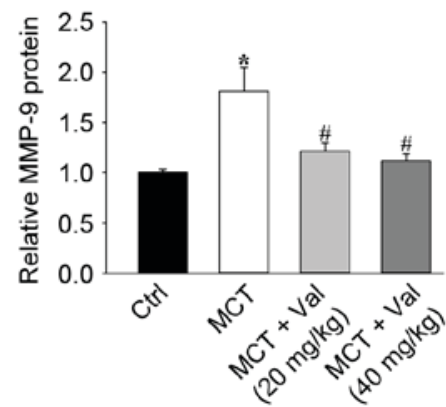

MCT + Val $\mathrm{MCT}+\mathrm{Val}$
$(20 \mathrm{mg} / \mathrm{kg})(40 \mathrm{mg} / \mathrm{kg})$

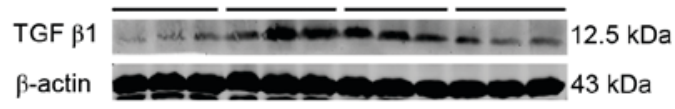

D

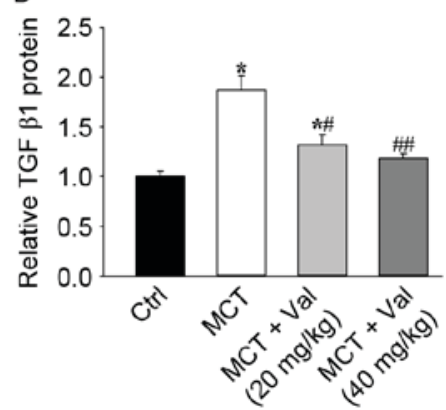

Figure 6. Effects of valsartan on MCT-induced instability of extracellular matrix and fibrosis in lung tissue. Representative blots of protein expression levels of (A) MMP2, -9 and TGF- $\beta 1$ following MCT treatment and two doses of valsartan. Quantification of protein expression levels of (B) MMP-2, (C) MMP-9 and (D) TGF- $\beta 1$ from western blots ( $\mathrm{n}=5$ rats per group). Results are expressed as the mean \pm standard error. ${ }^{*} \mathrm{P}<0.05$ vs. Ctrl group; ${ }^{~} \mathrm{P}<0.05$, ${ }^{\# \#} \mathrm{P}<0.01$ vs. MCT group. Ctrl, control; MCT, monocrotaline; MMP, matrix metalloproteinase; TGF- $\beta 1$, transforming growth factor- $\beta 1$; Val, valsartan.

cases of PH (10-13). However, further studies have demonstrated that losartan does not attenuate $\mathrm{PH}$ in rodents (24). There may be various reasons for these inconsistent results from the ARB on PH. Firstly, these cardioprotective effects may only be mediated in part via the AT1 receptor signaling pathway. Additionally, differing doses of ARBs may result in varying effects on PH. However, valsartan has a 20,000-fold greater affinity for AT1 compared with the AngII-type 2 receptor (25). The Valsartan in Heart Failure Trial (Val-HeFT) study demonstrated that the beneficial effects of the drug are maintained in patients with renal dysfunction at baseline and those experiencing early worsening of renal function (26). Furthermore, Katada et al (27) suggested that valsartan exerts greater positive effects on cognitive functions than amlodipine in elderly hypertensive patients, independent of the antihypertensive effects. In addition, valsartan reduces levels of inflammatory factors, ROS and expression of tissue plasminogen activator $(28,29)$. The present study demonstrated that valsartan reduced vascular remodeling, RVSP and RV hypertrophy in a dose-dependent manner. It is of note, that valsartan at $40 \mathrm{mg} / \mathrm{kg}$ revealed increased efficacy compared with $\mathrm{PH}$ rodents, whereas $20 \mathrm{mg} / \mathrm{kg}$ demonstrated only a marginal beneficial effect in attenuating $\mathrm{PH}$.

Accumulating evidence indicates that impairment of pulmonary vascular homeostasis is important in the pathobiology of PH (30). AngII stimulates expression of MMPs $(31,32)$ in vascular smooth muscle cells, which are important for ECM breakdown and cell migration. The matrix degrading enzymes MMP-2 and -9 are essential in mediating structural alterations in tissue growth, however increased MMP-2 or -9 activity may contribute to pathological lung vascular remodeling by promoting smooth muscle cell migration (33) and inflammatory cell infiltration (34). Previous studies have demonstrated that MMP-2 and -9 expression and activity are increased in the lung vasculature of PH rodents (35). MMP inhibition limits pulmonary vascular remodeling in MCT-induced (36) and hypoxia-induced PH (37). Conversely, Vieillard-Baron et al (36) reported that MMP inhibition 
increases pulmonary vascular remodeling in hypoxia-induced $\mathrm{PH}$. The present study demonstrated that valsartan decreased vascular remodeling induced by MCT. Valsartan additionally suppressed MCT-induced increase of MMP-2 and -9 expression. MMPs may therefore exhibit various effects in differing PH models at any different time point.

Additionally, valsartan suppressed TGF- $\beta 1$ expression in MCT-induced PH. TGF- $\beta 1$ is a cytokine that regulates numerous cellular responses. Increased TGF- $\beta 1$ expression has been identified as a maladaptive factor in PH (38), in part via activation of activin-like kinase 5, which promotes vascular smooth muscle cell proliferation (39). The repression of TGF- $\beta 1$ expression by valsartan may explain how it reduces smooth muscle cell proliferation in MCT-induced $\mathrm{PH}$. Another mechanism by which valsartan may reduce vascular smooth muscle cell proliferation is via inhibition of p42/44 ERK/MAPK activation. The ERK/MAPK signaling pathway is important for cell cycle progression in numerous cell types. AngII promotes p42/44 ERK/MAPK dependent proliferation of pulmonary artery smooth muscle cells via the AT1 receptor (40). The findings demonstrated that valsartan treatment suppressed MCT-induced p42/44 MAPK activation. The additional observation of decreased PCNA and cyclin D1 expression levels, suggested an additional mechanism by which valsartan prevents smooth muscle cell proliferation and the maladaptive vascular remodeling that drives PH. However, the present study is not able to exclude further potential mechanisms by which vascular remodeling may be modulated by valsartan.

In conclusion, valsartan suppressed pulmonary vascular remodeling and RV hypertrophy in MCT and hypoxia-induced $\mathrm{PH}$ animal models. These beneficial effects of valsartan may have occurred via inhibition of MAPK signaling and MMP expression. These findings suggest that valsartan may act as a valuable therapeutic approach for the treatment of $\mathrm{PH}$ in the future.

\section{Acknowledgements}

The present study was supported by the National Natural Science Foundation of China (grant no. 81270194 to D.X). The authors would like to thank Professor John Fassett from the Lillehei Heart Institute and the Cardiovascular Division, University of Minnesota (Minneapolis, MN, USA) for critical comments and suggestions.

\section{References}

1. Farber HW, Miller DP, Poms AD, Badesch DB, Frost AE, Muros-Le Rouzic E, Romero AJ, Benton WW, Elliott CG, McGoon MD and Benza RL: Five-Year outcomes of patients enrolled in the REVEAL Registry. Chest 148: 1043-1054, 2015.

2. Simonneau G, Gatzoulis MA, Adatia I, Celermajer D, Denton C, Ghofrani A, Gomez Sanchez MA, Krishna Kumar R, Landzberg M, Machado RF, et al: Updated clinical classification of pulmonary hypertension. J Am Coll Cardiol 62 (25 Suppl): D34-D41, 2013.

3. Opitz C, Rosenkranz S, Ghofrani HA, Grunig E, Klose H, Olschewski $\mathrm{H}$ and Hoeper M: ESC guidelines 2015 pulmonary hypertension: Diagnosis and treatment. Dtsch Med Wochenschr 141: 1764-1769, 2016.

4. Hurdman J, Condliffe R, Elliot CA, Davies C, Hill C, Wild JM, Capener D, Sephton P, Hamilton N, Armstrong IJ, et al: ASPIRE registry: Assessing the spectrum of pulmonary hypertension identified at a REferral centre. Eur Respir J 39: 945-955, 2012.
5. Thompson AA and Lawrie A: Targeting Vascular remodeling to treat pulmonary arterial hypertension. Trends Mol Med 23: 31-45, 2017

6. Chelladurai P, Seeger W and Pullamsetti SS: Matrix metalloproteinases and their inhibitors in pulmonary hypertension. Eur Respir J 40: 766-782, 2012.

7. Morrell NW, Atochina EN, Morris KG, Danilov SM and Stenmark KR: Angiotensin converting enzyme expression is increased in small pulmonary arteries of rats with hypoxia-induced pulmonary hypertension. J Clin Invest 96: 1823-1833, 1995

8. Orte C, Polak JM, Haworth SG, Yacoub MH and Morrell NW: Expression of pulmonary vascular angiotensin-converting enzyme in primary and secondary plexiform pulmonary hypertension. J Pathol 192: 379-384, 2000.

9. de Man FS, Tu L, Handoko ML, Rain S, Ruiter G, Francois C, Schalij I, Dorfmuller P, Simonneau G, Fadel E, et al: Dysregulated renin-angiotensin-aldosterone system contributes to pulmonary arterial hypertension. Am J Respir Crit Care Med 186: 780-789, 2012.

10. Morrell NW, Higham MA, Phillips PG, Shakur BH, Robinson PJ and Beddoes RJ: Pilot study of losartan for pulmonary hypertension in chronic obstructive pulmonary disease. Respir Res 6: 88, 2005.

11. Rondelet B, Kerbaul F, Van Beneden R, Hubloue I, Huez S, Fesler P, Remmelink M, Brimioulle S, Salmon I and Naeije R: Prevention of pulmonary vascular remodeling and of decreased BMPR-2 expression by losartan therapy in shunt-induced pulmonary hypertension. Am J Physiol Heart Circ Physiol 289: H2319-H2324, 2005.

12. Xie L, Lin P, Xie H and Xu C: Effects of atorvastatin and losartan on monocrotaline-induced pulmonary artery remodeling in rats. Clin Exp Hypertens 32: 547-554, 2010.

13. Okada M, Harada T, Kikuzuki R, Yamawaki H and Hara Y: Effects of telmisartan on right ventricular remodeling induced by monocrotaline in rats. J Pharmacol Sci 111: 193-200, 2009.

14. Saygili E, Rana OR, Saygili E, Reuter H, Frank K, Schwinger RH, Muller-Ehmsen J and Zobel C: Losartan prevents stretch-induced electrical remodeling in cultured atrial neonatal myocytes. Am J Physiol Heart Circ Physiol 292: H2898-H2905, 2007.

15. Ridker PM, Danielson E, Rifai N and Glynn RJ; Val-MARC Investigators: Valsartan, blood pressure reduction and C-reactive protein: Primary report of the Val-MARC trial. Hypertension 48: 73-79, 2006.

16. Anand IS, Kuskowski MA, Rector TS, Florea VG, Glazer RD, Hester A, Chiang YT, Aknay N, Maggioni AP, Opasich C, et al: Anemia and change in hemoglobin over time related to mortality and morbidity in patients with chronic heart failure: Results from Val-HeFT. Circulation 112: 1121-1127, 2005.

17. Croom KF and Keating GM: Valsartan: A review of its use in patients with heart failure and/or left ventricular systolic dysfunction after myocardial infarction. Am J Cardiovasc Drugs 4: 395-404, 2004.

18. National Research Council (US) Committee for the update of the guide for the care and use of laboratory animals: Guide for the care and use of laboratory animals. 8th edition, National Academies Press, Washington, DC, 2011

19. Xu D, Guo H, Xu X, Lu Z, Fassett J, Hu X, Xu Y, Tang Q, Hu D, Somani A, et al: Exacerbated pulmonary arterial hypertension and right ventricular hypertrophy in animals with loss of function of extracellular superoxide dismutase. Hypertension 58: 303-309, 2011.

20. Chen Y, Guo H, Xu D, Xu X, Wang H, Hu X, Lu Z, Kwak D, Xu Y, Gunther R, et al: Left ventricular failure produces profound lung remodeling and pulmonary hypertension in mice: Heart failure causes severe lung disease. Hypertension 59: 1170-1178, 2012.

21. Pacher P, Nagayama T, Mukhopadhyay P, Bátkai S and Kass DA: Measurement of cardiac function using pressure-volume conductance catheter technique in mice and rats. Nat Protoc 3: 1422-1434, 2008

22. Fan YF, Zhang R, Jiang X, Wen L, Wu DC, Liu D, Yuan P, Wang YL and Jing ZC: The phosphodiesterase-5 inhibitor vardenafil reduces oxidative stress while reversing pulmonary arterial hypertension. Cardiovasc Res 99: 395-403, 2013.

23. Abe K, Shimokawa H, Morikawa K, Uwatoku T, Oi K, Matsumoto Y, Hattori T, Nakashima Y, Kaibuchi K, Sueishi K and Takeshit A: Long-term treatment with a Rho-kinase inhibitor improves monocrotaline-induced fatal pulmonary hypertension in rats. Circ Res 94: 385-393, 2004. 
24. Cassis LA, Rippetoe PE, Soltis EE, Painter DJ, Fitz R and Gillespie MN: Angiotensin II and monocrotaline-induced pulmonary hypertension: Effect of losartan (DuP 753), a nonpeptide angiotensin type 1 receptor antagonist. J Pharmacol Exp Ther 262: 1168-1172, 1992.

25. Destro M, Cagnoni F, D'Ospina A, Ricci AR, Demichele E, Peros E, Zaninelli A and Preti P: Role of valsartan, amlodipine and hydrochlorothiazide fixed combination in blood pressure control: An update. Vasc Health Risk Manag 6: 253-260, 2010.

26. Lesogor A, Cohn JN, Latini R, Tognoni G, Krum H, Massie B, Zalewski A, Kandra A, Hua TA and Gimpelewicz C: Interaction between baseline and early worsening of renal function and efficacy of renin-angiotensin-aldosterone system blockade in patients with heart failure: Insights from the Val-HeFT study. Eur J Heart Fail 15: 1236-1244, 2013.

27. Katada E, Uematsu N, Takuma Y and Matsukawa N: Comparison of effects of valsartan and amlodipine on cognitive functions and auditory p300 event-related potentials in elderly hypertensive patients. Clin Neuropharmacol 37: 129-132, 2014.

28. Manabe S, Okura T, Watanabe S, Fukuoka T and Higaki J: Effects of angiotensin II receptor blockade with valsartan on pro-inflammatory cytokines in patients with essential hypertension. J Cardiovasc Pharmacol 46: 735-739, 2005.

29. Yang J, Jiang H, Yang J, Ding JW, Chen LH, Li S and Zhang XD: Valsartan preconditioning protects against myocardial ischemia-reperfusion injury through TLR4/NF-kappaB signaling pathway. Mol Cell Biochem 330: 39-46, 2009.

30. Schraufnagel DE and Schmid A: Pulmonary capillary density in rats given monocrotaline. A cast corrosion study. Am Rev Respir Dis 140: 1405-1409, 1989.

31. Kopaliani I, Martin M, Zatschler B, Bortlik K, Müller B and Deussen A: Cell-specific and endothelium-dependent regulations of matrix metalloproteinase-2 in rat aorta. Basic Res Cardiol 109: 419, 2014

32. Guo RW, Yang LX, Wang H, Liu B and Wang L: Angiotensin II induces matrix metalloproteinase-9 expression via a nuclear factor-kappaB-dependent pathway in vascular smooth muscle cells. Regul Pept 147: 37-44, 2008.

33. Pullamsetti S, Krick S, Yilmaz H, Ghofrani HA, Schudt C, Weissmann N, Fuchs B, Seeger W, Grimminger F and Schermuly RT: Inhaled tolafentrine reverses pulmonary vascular remodeling via inhibition of smooth muscle cell migration. Respir Res 6: 128, 2005.
34. George $\mathrm{J}$ and D'Armiento J: Transgenic expression of human matrix metalloproteinase-9 augments monocrotaline-induced pulmonary arterial hypertension in mice. J Hypertens 29: 299-308, 2011

35. Frisdal E, Gest V, Vieillard-Baron A, Levame M, Lepetit H, Eddahibi S, Lafuma C, Harf A, Adnot S and Dortho MP: Gelatinase expression in pulmonary arteries during experimental pulmonary hypertension. Eur Respir J 18: 838-845, 2001.

36. Vieillard-Baron A, Frisdal E, Raffestin B, Baker AH, Eddahibi S, Adnot S and D'Ortho MP: Inhibition of matrix metalloproteinases by lung TIMP-1 gene transfer limits monocrotaline-induced pulmonary vascular remodeling in rats. Hum Gene Ther 14: 861-869, 2003.

37. Zaidi SH, You XM, Ciura S, Husain M and Rabinovitch M: Overexpression of the serine elastase inhibitor elafin protects transgenic mice from hypoxic pulmonary hypertension. Circulation 105: 516-521, 2002.

38. Long L, Crosby A, Yang X, Southwood M, Upton PD, Kim DK and Morrell NW: Altered bone morphogenetic protein and transforming growth factor-beta signaling in rat models of pulmonary hypertension: Potential for activin receptor-like kinase-5 inhibition in prevention and progression of disease. Circulation 119: 566-576, 2009.

39. Thomas M, Docx C, Holmes AM, Beach S, Duggan N, England K, Leblanc C, Lebret C, Schindler F, Raza F, et al: Activin-like kinase 5 (ALK5) mediates abnormal proliferation of vascular smooth muscle cells from patients with familial pulmonary arterial hypertension and is involved in the progression of experimental pulmonary arterial hypertension induced by monocrotaline. Am J Pathol 174: 380-389, 2009.

40. Morrell NW, Upton PD, Kotecha S, Huntley A, Yacoub MH, Polak JM and Wharton J: Angiotensin II activates MAPK and stimulates growth of human pulmonary artery smooth muscle via AT1 receptors. Am J Physiol 277: L440-L448, 1999. 